\title{
Rancang Bangun Sistem Alarm Gempa Bumi Menggunakan Prinsip Gaya Pegas dan Penginderaan Medan Magnetik
}

\author{
Andre Rizki Naldi*, Wildian \\ Laboratorium Elektronika dan Instrumentasi, Jurusan Fisika \\ Fakultas Matematika dan Ilmu Pengetahuan Alam, Universitas Andalas \\ Kampus Limau Manis, Padang, 25163, Indonesia \\ *andrerizki672@gmail.com
}

\begin{abstract}
ABSTRAK
Telah dirancang sistem alarm gempa bumi dengan memanfaatkan prinsip gaya pegas dan penginderaan medan magnet menggunakan sensor Efek Hall. Sistem terdiri dari dua perangkat keras yaitu sistem sensor Efek Hall dan mikrokontroler Atmega 328. Pengujian alarm gempa dilakukan dengan menjatuhkan massa dengan memvariasikan ketinggian beban yaitu $20 \mathrm{~cm}, 30 \mathrm{~cm}$, and $40 \mathrm{~cm}$, variasi jarak jatuh ke sensor 10 - $200 \mathrm{~cm}$, dan variasi massa beban jatuh (200 g, $400 \mathrm{~g}$, dan $600 \mathrm{~g})$. Acuan yang digunakan untuk menandakan getaran gempa bumi adalah 2 MMI (Modified Mercally Intansity) yaitu benda-benda ringan yang digantung bergoyang. Dari hasil pengujian didapatkan bahwa sensor masih peka dalam mendeteksi getaran dengan semua variasi ketinggian dan massa beban pada jarak maksimum $90 \mathrm{~cm}$.
\end{abstract}

Kata-kunci : sistem alarm gempa, medan magnet, sensor Efek Hall, MMI, Mikrokontroler Atmega 328

\section{ABSTRACT}

Earthquake alarm system has been designed by utilizing the principle of spring force and magnetic field sensing using the hall effect sensor. The system consists of two hardwares, namely the hall effect sensor system and atmega 328 microcontroller. Earthquake alarm testing is carried by drop a mass with variation of height $20 \mathrm{~cm}, 30 \mathrm{~cm}$, and $40 \mathrm{~cm}$, the falling distance to sensor $10-200 \mathrm{~cm}$, and the weight of the mass of $200 \mathrm{~g}, 400 \mathrm{~g}$, and $600 \mathrm{~g}$. The reference value used to indicate earthquake vibrations occurence is 2 MMI (light hung object sway). From the test results, it is found that the sensor is sensitive in detecting vibrations with all variations in altitude and mass load at a maximum distance of 90 $\mathrm{cm}$

Keywords: earthquake alarm system, magnetic field, Hall effect sensor, MMI, Atmega microcontroller 328

\section{PENDAHULUAN}

Sumatera Barat adalah daerah Indonesia yang secara geografis termasuk daerah rawan bencana, terutama bencana alam seperti gempa, tanah longsor, banjir, tsunami, gunung meletus dan lain sebagainya, yang dapat menyebabkan kerusakan lingkungan, kerugian harta benda, dampak psikologi, dan korban jiwa (PERDA Sumbar, 2007) .

Di kota padang gempa adalah hal yang biasa terjadi jika berkekuatan di bawah 3 SR, mayoritas masyarakat tidak merasakan keberadaan gempa. Namun, saat gempa terjadi sekitar 78 SR, kekuatan ini cukup meluluh lantakkan bangunan-bangunan dan tempat umum lainnya. Potensi gempa sering sekali berpusat di daerah laut yang berkemungkinan berpotensi tsunami. Hal inilah yang membuat masyarakat padang merasa sangat cemas (Afriani, 2010).

Gempa bisa terjadi kapan saja saat beraktivitas, santai ataupun sedang beristirahat malam. Karena itulah perlu sekali sebuah alat yang dapat mendeteksi getaran terhadap gempa dirumah yang selalu beroperasi selama 24 jam untuk memperingatkan, dan membangunkan kita saat gempa terjadi (Setiono, 2010).

Berbagai sistem peringatan dini telah banyak dikembangkan. Pada tahun 2011, Jamal telah membuat alat pendeteksi gempa dengan metode FM berbasis personal computer. Alat ini bekerja sangat baik dengan menghasilkan sebuah simulasi yang nantinya diharuskan membuat stasiun pengukuran di beberapa tempat. (Mulyono, 2013) membuat alat pendeteksi gempa untuk rumah dan gedung bertingkat menggunakan sensor accelerometer MMA7260Q. Sensor accelerometer adalah sensor yang dapat mendeteksi getaran dalam arah horizontal maupun vertikal (Rakhmadi, 2013 ). Tahun 2015, Rahman membuat alat pendeteksi gempa menggunakan sensor piezoelektrik. Kelemahan alat ini adalah jarak yang bisa diindera masih sangat pendek yaitu mampu mengindera pada jarak maksimum $100 \mathrm{~cm}$. 
Dari pembahasan di atas dibuat sebuah sistem peringatan gempa bumi Menggunakan Prinsip Gaya Pegas Dan Penginderaan Medan Magnetik yang dapat membantu pemerintah atau masyarakat dalam mengatasi bencana gempa bumi. Prinsip kerja dari alat ini adalah sensor pengukur getaran ditanam di dalam tanah dan diberi magnet permanen di dalamnya. Saat ada tekanan dari atas maka pegas akan tertekan kebawah sehingga sensor mendekati magnet permanen, saat mendekati magnet permanen maka medan magnet yang ditimbulkan akan sangat besar dan akan mempercepat kepekaan terhadap getaran yang ditimbulkan oleh tekanan tadi, medan magnet inilah yang langsung diindera oleh sensor magnet, sensor berfungsi untuk mengukur getaran gempa secara vertikal dan mengirimkan informasi ke alarm dan langsung memberikan instruksi-instruksi untuk memberikan peringatan dini gempa.

\section{METODE PENELITIAN}

\subsection{Perancangan Blok Sistem}

Perancangan diagram blok sistem ini merupakan logika berpikir dalam mencapai hasil akhir yang bertujuan untuk memberikan instruksi peringatan dini gempa bumi melalui buzzer yang berbunyi. Sensor gempa bumi yang digunakan adalah sensor magnetik yang menggunakan prinsip gaya pegas. Jika ada goncangan vertikal yang diberikan, maka pegas akan bergerak mendekati magnet permanen yang ditanam di bawah sensor magnet, sehingga jarak antara sensor magnet dan magnet permanen menjadi dekat yang menghasilkan medan magnet yang kuat, medan magnet ini yang akan diindera sensor. Sensor akan mengolah data dan merubah besaran magnet menjadi besaran listrik yang akan diolah lagi menjadi besaran fisis berupa keluaran bunyi dari buzzer dan LCD. Perancangan diagram blok sistem dilihat pada Gambar 1.

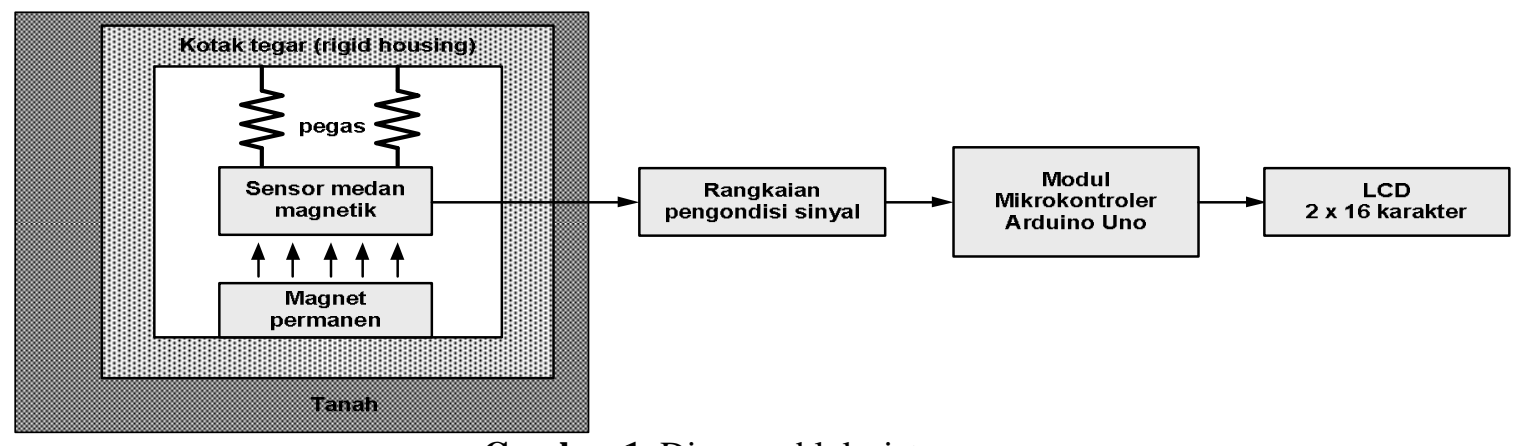

Gambar 1. Diagram blok sistem

\subsection{Karakterisasi Sensor Efek Hall}

Karakterisasi sensor dilakukan untuk mengetahui apakah sensor sesuai dengan datasheet dan apakah dapat bekerja dengan baik. Rangkaian ini merupakan gabungan dari rangkaian catu daya, rangkaian sistem sensor, rangkaian pengondisi sinyal, modul Mikrokontroler Ardiuno Uno R3, LCD, serta rangkaian alarm peringatan dini (Novianta, 2012).

\subsection{Perancangan Program pada PC}

Perancangan program menggunakan software BASCOM-AVR untuk menjalankan perintah yang telah diprogram. Program diawali dengan inisialisasi pin mikrokontroler. Program yang akan dibuat sesuai dengan port yang telah ditentukan sebagai masukan dan keluaran. Port A0 sebagai masukan pada sistem sensor, sedangkan port C3, C4, C5, dan C7 digunakan sebagai port keluaran berupa bunyi alarm. Sebelum perancangan program pada PC terlebih dahulu digambarkan dalam bentuk diagram alir yang dijadikan sebagai alur pemikiran pembuatan program (Guntara, 2014) .

\subsection{Perancangan Bentuk Prototype Sistem Peringatan Dini Gempa Bumi}

Prototype terdiri dari kotak sistem sensor gempa bumi yang dilengkapi dengan pegas yang akan memendek jika menerima tekanan yang mengakibatkan jarak sensor dengan magnet batang menjadi lebih dekat dan menimbulkan medan magnet, medan magnet inilah yang akan diindera oleh sensor tersebut. Dari sensor diteruskan pada rangkaian pengondisi sinyal dan 
langsung pada mikrokontroler yang dibuat seperti kotak agar terjaga dari kerusakan. Setelah itu alarm akan berbunyi sebagaimana yang telah diprogram. Pengujian akhir prototype dilakukan dengan mensimulasikan terjadinya gempa bumi. Massa gerak tanah yang akan memberikan tekanan pada kotak yang berisi sistem sensor gempa bumi akan bekerja. Jika pada simulasi gempa bumi terjadi maka lampu indikator dan alarm akan berbunyi sebagai peringatan dini terjadinya gempa bumi. Simulasi dilakukan di atas papan berukuran $200 \mathrm{~cm}$ dengan menjatuhkan variasi beban untuk melihat perubahan energi yang ditimbulkan (Giancolli, 1998).

\section{HASIL DAN DISKUSI}

Berdasarkan rancangan alat yang telah dibuat maka dihasilkan sebuah prototype alarm gempa bumi. Bunyi alarm gempa bumi dikeluarkan dalam bentuk Buzzer, dan tegangan keluaran yang ditampilkan dalam bentuk LCD. Bentuk prototype alarm gempa dapat dilihat pada gambar 2 .

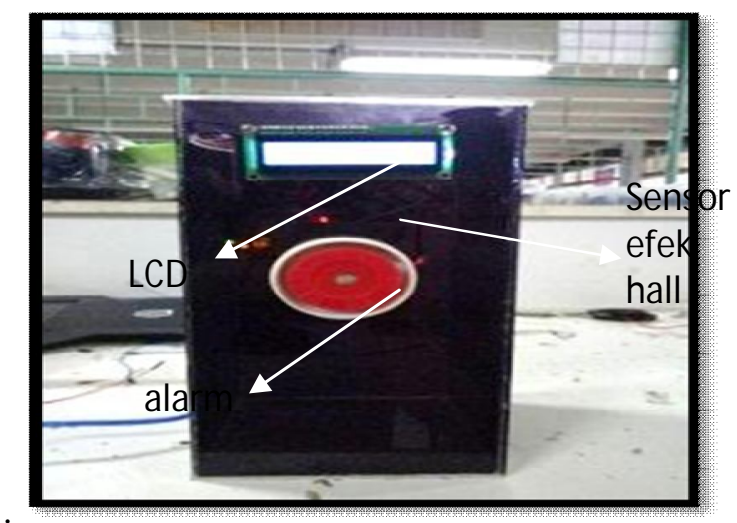

Gambar 2 Prototype alarm gempa

Sistem kinerja alat peringatan dini gempa bumi dilakukan uji sebagai berikut:

\subsection{Karakterisasi Sensor Efek Hall}

Uji kinerja dilakukan untuk melihat kepekaan sensor terhadap medan magnetik. Pengujian dilakukan dengan mendekatkan magnet batang ke sensor efek hall dan didapatkan sensor peka pada jarak $0 \mathrm{~cm}$ sampai $4 \mathrm{~cm}$ dengan tegangan masukan 5 volt. Hasil karakterisasi sensor Efek Hall dapat dilihat pada Tabel 1.

Tabel 1. Karakterisasi sensor

\begin{tabular}{cc}
\hline Jarak ke sensor $(\mathrm{cm})$ & Tegangan keluaran $(\mathrm{V})$ \\
\hline 0.5 & 4.22 \\
1.0 & 3.94 \\
1.5 & 3.8 \\
2.0 & 3.1 \\
2.5 & 2.75 \\
3.0 & 2.11 \\
3.5 & 1.54 \\
4.0 & 0.6 \\
4.5 & 0.2 \\
5.0 & 0 \\
\hline
\end{tabular}

Tabel 1 menjelaskan bahwa semakin kecil jarak magnet ke sensor maka semakin besar nilai tegangan keluaran sensor, sehingga jarak maksimum sensor mengindera medan magnetik yang diperoleh adalah $4 \mathrm{~cm}$. Berdasarkan jarak tersebut magnet batang dipasang pada jarak 4 $\mathrm{cm}$ agar alat dapat bekerja dengan baik. Grafik hubungan tegangan keluaran dengan jarak dapat dilihat pada Gambar 3. 


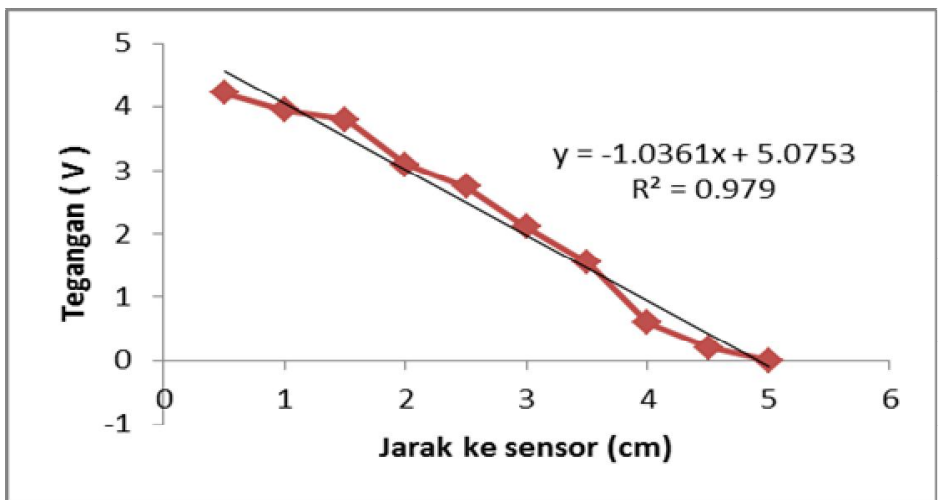

Gambar 3. Grafik hubungan tegangan keluaran terhadap jarak ke sensor

\subsection{Pengujian Prototype Secara Keseluruhan}

Pengujian alat secara keseluruhan dilakukan dengan memvariasikan massa beban jatuh yaitu (200 g, 400 g, 600 g), variasi jarak ke sensor, dan variasi ketinggian jatuh beban yaitu (20 $\mathrm{cm}, 30 \mathrm{~cm}, 40 \mathrm{~cm}$ ). Hasil pengujian secara keseluruhan dapat dilihat pada Tabel 2, Tabel 3 , Tabel 4.

Tabel 2. Pengujian alat dengan massa beban $200 \mathrm{~g}$

\begin{tabular}{|c|c|c|c|c|c|c|c|}
\hline \multirow{3}{*}{ No } & \multirow{3}{*}{$\begin{array}{l}\text { Jarak } \\
(\mathbf{x}) \mathrm{cm}\end{array}$} & \multicolumn{6}{|c|}{ Ketinggian Jatuh } \\
\hline & & \multicolumn{2}{|c|}{$20 \mathrm{~cm}$} & \multicolumn{2}{|c|}{$30 \mathrm{~cm}$} & \multicolumn{2}{|c|}{$40 \mathrm{~cm}$} \\
\hline & & Relay & Buzzer & Relay & Buzzer & Relay & Buzzer \\
\hline 1 & $10-70$ & Tidak aktif & Tidak aktif & Tidak aktif & Tidak aktif & Tidak aktif & Tidak aktif \\
\hline 2 & 80 & Tidak aktif & Tidak aktif & Tidak aktif & Tidak aktif & Aktif & Aktif \\
\hline 3 & 90 & Tidak aktif & Tidak aktif & Aktif & Aktif & Aktif & Aktif \\
\hline 4 & 100 & Tidak aktif & Tidak aktif & Tidak aktif & Tidak aktif & Aktif & Aktif \\
\hline 5 & $110-200$ & Tidak aktif & $\begin{array}{l}\text { Tidak } \\
\text { Aktif }\end{array}$ & Tidak aktif & Tidak aktif & Tidak aktif & Tidak aktif \\
\hline
\end{tabular}

Tabel 3. Pengujian dan pengamatan alat terhadap beban $400 \mathrm{~g}$

\begin{tabular}{|c|c|c|c|c|c|c|c|}
\hline \multirow{3}{*}{ No } & \multirow{3}{*}{$\begin{array}{l}\text { Jarak (x) } \\
\text { cm }\end{array}$} & \multicolumn{6}{|c|}{ Ketinggian Jatuh } \\
\hline & & \multicolumn{2}{|c|}{$20 \mathrm{~cm}$} & \multicolumn{2}{|c|}{$30 \mathrm{~cm}$} & \multicolumn{2}{|c|}{$40 \mathrm{~cm}$} \\
\hline & & Relay & Buzzer & Relay & Buzzer & Relay & Buzzer \\
\hline 1 & $10-70$ & Tidak aktif & Tidak aktif & Tidak aktif & Tidak aktif & Tidak aktif & Tidak aktif \\
\hline 2 & 80 & Tidak aktif & Tidak aktif & Tidak aktif & Tidak aktif & Aktif & Aktif \\
\hline 3 & 90 & Tidak aktif & Aktif & Aktif & Aktif & Aktif & Aktif \\
\hline 4 & 100 & Aktif & Tidak aktif & Aktif & Aktif & Aktif & Aktif \\
\hline 5 & 110 & Tidak aktif & Tidak aktif & Tidak aktif & Tidak aktif & Aktif & Aktif \\
\hline 6 & $120-200$ & Tidak aktif & Tidak aktif & Tidak aktif & Tidak aktif & Tidak aktif & Tidak aktif \\
\hline
\end{tabular}

Tabel 4. Pengujian dan pengamatan alat terhadap massa beban $600 \mathrm{~g}$

\begin{tabular}{|c|c|c|c|c|c|c|c|}
\hline \multirow{3}{*}{ No } & \multirow{3}{*}{$\begin{array}{l}\text { Jarak } \\
(\mathbf{x}) \mathrm{cm}\end{array}$} & \multicolumn{6}{|c|}{ Ketinggian Jatuh } \\
\hline & & \multicolumn{2}{|c|}{$20 \mathrm{~cm}$} & \multicolumn{2}{|c|}{$30 \mathrm{~cm}$} & \multicolumn{2}{|c|}{$40 \mathrm{~cm}$} \\
\hline & & Relay & Buzzer & Relay & Buzzer & Relay & Buzzer \\
\hline 1 & $10-30$ & Tidak aktif & Tidak aktif & Tidak aktif & Tidak aktif & Tidak aktif & Tidak aktif \\
\hline 2 & 40 & Tidak aktif & Tidak aktif & Tidak aktif & Tidak aktif & Aktif & Aktif \\
\hline 3 & 50 & Tidak aktif & Tidak aktif & Tidak aktif & Tidak aktif & Aktif & Aktif \\
\hline 4 & 60 & Tidak aktif & Tidak aktif & Aktif & Aktif & Aktif & Aktif \\
\hline 5 & 70120 & Aktif & Aktif & Aktif & Aktif & Aktif & Aktif \\
\hline 6 & $130-140$ & Tidak aktif & Tidak aktif & Aktif & Aktif & Aktif & Aktif \\
\hline 7 & 150 & Tidak aktif & Tidak aktif & Tidak aktif & Tidak aktif & Aktif & Aktif \\
\hline 8 & $160-200$ & Tidak aktif & Tidak aktif & Tidak aktif & Tidak aktif & Tidak aktif & Tidak aktif \\
\hline
\end{tabular}

Pada Tabel 2 pengujian dan pengamatan alat terhadap massa beban $200 \mathrm{~g}$, dapat dilihat bahwa pada beban 200 g alarm berbunyi pada ketinggian jatuh $30 \mathrm{~cm}$ dengan jarak ke alat 90 $\mathrm{cm}$, pada ketinggian $40 \mathrm{~cm}$ alarm berbunyi dengan jarak ke alat $100 \mathrm{~cm}$. 
Pada Tabel 3 pengujian dan pengamatan alat terhadap massa beban $400 \mathrm{~g}$, dapat dilihat bahwa pada ketinggian jatuh $20 \mathrm{~cm}$ alarm berbunyi dengan jarak ke alat $100 \mathrm{~cm}$, ketinggian jatuh $30 \mathrm{~cm}$ alarm berbunyi dengan jarak ke alat $100 \mathrm{~cm}$ dan $90 \mathrm{~cm}$, ketinggian jatuh $40 \mathrm{~cm}$ alarm berbunyi dengan jarak ke alat $110 \mathrm{~cm}, 100 \mathrm{~cm}$, dan $90 \mathrm{~cm}$.

Pada Tabel 4 pengujian dan pengamatan alat terhadap massa beban $600 \mathrm{~g}$, dapat dilihat bahwa pada ketinggian jatuh $20 \mathrm{~cm}$ alarm berbunyi dengan jarak ke alat $120 \mathrm{~cm}, 110 \mathrm{~cm}, 100$ $\mathrm{cm}, 90 \mathrm{~cm}, 80 \mathrm{~cm}$, dan $70 \mathrm{~cm}$. pada ketinggian $30 \mathrm{~cm}$ alarm berbunyi dengan jarak ke alat 140 $\mathrm{cm}, 130 \mathrm{~cm}, 120 \mathrm{~cm}, 110 \mathrm{~cm}, 100 \mathrm{~cm}, 90 \mathrm{~cm}, 80 \mathrm{~cm}, 70 \mathrm{~cm}$, dan $60 \mathrm{~cm}$. Pada ketinggian jatuh $40 \mathrm{~cm}$ alarm berbunyi dengan jarak ke alat $150 \mathrm{~cm}, 140 \mathrm{~cm}, 130 \mathrm{~cm}, 120 \mathrm{~cm}, 110 \mathrm{~cm}, 100 \mathrm{~cm}$, $90 \mathrm{~cm}, 80 \mathrm{~cm}, 70 \mathrm{~cm}, 60 \mathrm{~cm}, 50 \mathrm{~cm}, 40 \mathrm{~cm}$.

Berdasarkan Tabel 2, Tabel 3, dan Tabel 4 menjelaskan bahwa semakin berat beban jatuh maka semakin kuat getaran yang akan ditimbulkan terbukti dari aktifnya relay dan buzzer.

\section{KESIMPULAN}

Berdasarkan data yang diperoleh pada penelitian ini, didapatkan beberapa kesimpulan yaitu; Rancang sistem alarm gampa bumi berbasis mikrokontroler Atmega 328 menggunakan sensor Efek Hall meliputi dua sistem yaitu otomatisasi pengaktifan buzzer dan menampilkan tegangan keluaran dari sensor. Hasil pengujian sensor menunjukan bahwa sensitivitas sensor baik dapat dilihat dengan nilai linearitas $\mathrm{R}^{2}=0,979$. Buzzer yang digunakan pada sistem mampu bekerja dengan baik ketika nilai tegangan keluaran $>2700 \mathrm{mV}$. Variasi uji alat terdiri dari variasi massa beban $(200 \mathrm{~g}, 400 \mathrm{~g}$, dan $600 \mathrm{~g}$ ), variasi ketinggian jatuh $(20 \mathrm{~cm}, 30 \mathrm{~cm}$, dan 40 $\mathrm{cm})$, variasi jarak dengan alat $(10 \mathrm{~cm}-200 \mathrm{~cm})$. Hasil yang diperoleh bahwa semakin besar massa beban maka semakin besar getaran yang ditimbulkan terbukti dengan berbunyinya buzzer atau alarm. Alat dapat mendeteksi getaran dari skala 2 MMI - 12 MMI.

\section{DAFTAR PUSTAKA}

Afriani, F. 2010. Design Sistem Peringatan Dini Gempa Bumi Menggunakan Sensor Efek Hall UGN3503 berbasis Mikrokontroler ATMEGA8535. Jurnal FMIPA UNP 5(4):234-241.

Giancolli, D.C ., 1998. Fisika, Jilid 2, Edisi kelima, Erlangga, Jakarta.

Guntara, F., 2014, Rancang Bangun Prototipe Spbu-Mini Berbasis Mikrokontroler Atmega8535 dengan Keluaran Berdasarkan Nilai Masukan dalam Rupiah, Skripsi, FMIPA, UNAND, Padang.

Jamal, Z. 2011. Pendeteksi Gempa dengan Metode FM Berbasis Personal Computer. Jurnal Informatika Bandar-Lampung 11 (1):77-89

Mulyono, H . 2013. Prototype Sistem Pendeteksi Gempa Untuk Rumah/Kantor Berbasis Mikrokontroler Menggunakan Sensor MMA7260Q. Jurnal Teknologi Informasi Dan Pendidikan UNILA 6(2):153-167.

Novianta, M.A. 2012. Sistem Deteksi Dini Gempa Bumi Berdasarkan Fluktuasi Medan Magnet Menggunakan Sensor Mems. Jurnal Jurusan Teknik Elektro Institut Sains \& Teknologi AKPRIND 16(1):35-44

Rahman, M.N. 2015. Rancang Bangun Sistem Alarm Gempa Bumi Berbasis Mikrokontroler Avr ATMEGA 16 Menggunakan Sensor Piezoelektrik. Jurnal Fisika Unand 4 (4):350357.

Rakhmadi, I.P. 2013. Purwarupa Sistem Pemantau Getaran Pada Bangunan Bertingkat Dua Menggunajan Sensor Akselerometer. Jurnal Jurusan Ilmu Komputer Dan Elektronika, Fmipa,UGM,Yogyakarta 3(2):137-146.

Republik Indonesia, 2007. PERDA Sumbar No.5 Tahun 2007 Tentang Penanggulangan Bencana.

Setiono, A. 2010. Pembuatan Dan Uji Coba Data Logger Berbasis Mikrokontroler Atmega32 Untuk Monitoring Pergeseran Tanah. Jurnal Fisika ISSN 0854-3046 Himpunan Fisika Indonesia 10 (2):83-9 